\title{
Failures to Compute
}

\author{
Cyrus C. M. Mody
}

$\mathrm{E}$ xperts sometimes disagree with each other. Dispute and debate, after all, are fundamental to the hammering out of scientific knowledge. But when experts differ on matters of national interest, the public and its policy elites are placed in the uncomfortable position of deciding which experts to believe. Every country referees experts' squabbles,

Arguments That Count
Physics, Computing, and
Missile Defense, 1949-2012
by Rebecca Slayton
MIT Press, Cambridge, MA,
2013. 337 pp. \$35, £24.95.
ISBN 9780262019446 .
Inside Technology.

modified organisms, and other controversies where the public struggles to decide which experts to believe. After all, missile defense has not often been a front-page issue during the present presidential administration-although Slayton reminds readers that BMD continues to complicate the United States's relationships with many other countries, and she strongly implies that the Obama administration has hardly been more cautious than its predecessors in throwing money at an expensive, unproven, and potenbut in the United States such imbroglios are common. As recent historical work on climate change-most notably Naomi Oreskes and Erik Conway's Merchants of Doubt (1) - has shown, techno-political disputes in the United States are easily amplified by the country's traditions of populist rhetoric, pliant spokesexperts subsidized by vested interests, and journalistic commitment to "balance."

Rebecca Slayton's Arguments That Count examines one such controversy, that over the feasibility and utility of ballistic missile defense (BMD), through the course of almost 70 years. In her conclusion, Slayton (a science policy scholar at Stanford University) suggests that some aspects of the BMD debate can be generalized to other casessuch as climate change or genetically modified organisms - where disputatious experts have tried to craft arguments that will persuade the public or its policy-makers. In particular, she offers a new sociological concept, the "disciplinary repertoire," as a tool for understanding how different kinds of experts latch onto different arguments or present them in varying ways. These repertoires are "the quantitative rules, codified knowledge, and habits of problem solving that enable experts to structure, estimate, and quantify uncertain technological futures. Disciplinary repertoires allow experts to rhetorically distinguish subjective, politically controversial aspects of a problem from putatively objective, technical realities."

In a sense, it's fortunate that Slayton makes the case that BMD can tell us something about climate change, genetically

The reviewer is at the Department of History, Rice Univesity, Houston, TX 77251-1892, USA. E-mail: cm6@rice.edu tially destabilizing technology. Ballistic missile defense is similar enough to other politically charged technologies that it can tell us something about that general category of dispute, but even when dormant it is always close enough to erupting into controversy again that the arguments Slayton examines will no doubt resurface in the public sphere once more.

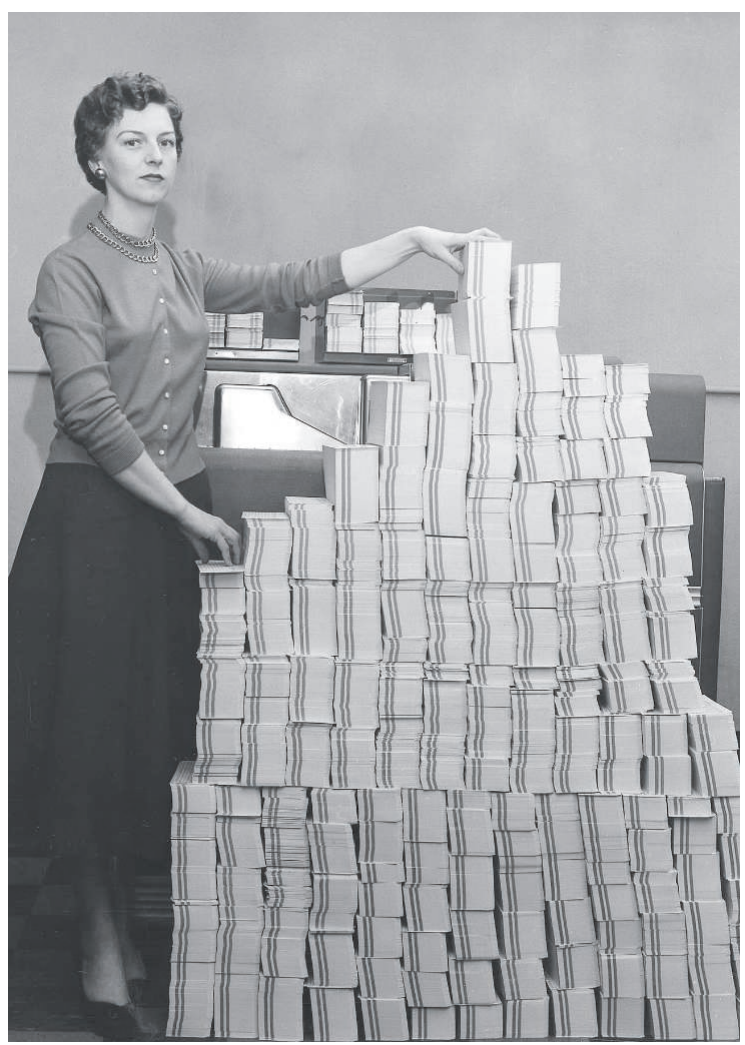

Potential for errors. Programmer Madeleine Carey with the 60,000 punch cards that contained the master program for the SAGE air defense system.
As a continually controversial not-yetexistent technology, BMD has had its history written many times - by technical and policy participants, political scientists, sociologists, and historians. Yet Slayton finds an ingenious and novel way to tell the history of missile defense systems anew: as a stage on which physicists and computing expertscomputer professionals? software engineers? this group's muddled identity is part of Slayton's point - performed for one another and for policy-makers and the public, while using those performances to forward their individual and community objectives.

For the most part, Slayton focuses on elite practitioners, both within the physics and science policy establishment and among those trying to forge a professional identity for programmers. We learn quite a bit about the importance of BMD in the careers of scientists and engineers who are more (and justly) famous for other things. These include physicists Herbert York, Hans Bethe, Jerome Wiesner, Dick Garwin, and Harold Brown as well as, on the computing side, Daniel McCracken, Fred Brooks, Edward David, and J. C. R. Licklider. Slayton's focus on the elite gives her narrative an oblique sensibility, because for most of the characters BMD was a sideshow (if an incredibly important one).

Yet there is a strong historical reason for looking to technical elites' relationships with BMD. Since at least the 1930s, plans for knocking enemy weapons out of the sky before they strike the homeland were a critical point of entry for technical experts into the higher strata of war- and policy-making in the United States and allied nations. Even before the atomic bomb made J. Robert Oppenheimer and Edward Teller such influential figures, air defense had done the same for Henry Tizard, P. M. S. Blackett, and Vannevar Bush. Postwar, physicists who developed radar for air defense - particularly at the Radiation Laboratory at the Massachusetts Institute of Technology-rose quickly in both academia and government.

One of Slayton's major contributions is to tease out the continuities and discontinuities between air defense and BMD. Elite physicists leveraged the threat of a Soviet bomber attack to create quintessential Cold 
War institutions, such as Lincoln Laboratory, that blurred the lines of academia and government and to pour money into efforts to develop digital computers such as SAGE (Semi-Automatic Ground Environment) and Project Whirlwind. Many of the same elite physicists (e.g., York, Garwin, and Bethe), however, were later opposed to the development of a comprehensive BMD system, largely on the grounds that it could destabilize nuclear diplomacy while providing little protection. Physicists who criticized the Johnson and Nixon administrations' desire for missile defense risked their careers and ultimately contributed to the decline in American politicians' deference toward technical expertise, even if their arguments ought to have counted.

Curiously, physicists who opposed a largescale missile defense did not initially identify software errors as a potential source of catastrophic failure. As Slayton shows, physicists involved in nuclear policy assumed (somewhat hilariously) that programming such a system would be cheap, fast, easy, and reliable. The reality, of course, was otherwise. Indeed, perhaps Slayton's most notable contribution is to show how much missile defense fostered the formation of professional institutions for software engineering as well as the development of new computer languages, proofs of program reliability (and, more generally, error-checking algorithms), standardization of software across different machines, and administrative methods for managing large programming projects. Ironically, the military's support for the emergence of a self-confident software engineering community yielded a new argument against BMD: that no software program complex enough to control a missile defense system could be shown to be free of errors that would render it inoperative the first (and only) time it was asked to do its job.

That argument remained bottled up through the 1970s-Slayton shows, for instance, that Daniel McCracken's Computer Professionals Against the ABM (Anti-Ballistic Missile) garnered many colleagues' tacit agreement but few offered public support. Later, however, software engineers' arguments counted more, with computer scientist David Parnas's well-publicized resignation from a Strategic Defense Initiative review panel in the 1980s and the contribution of software glitches to Patriot missile failures during the first Gulf War. Physical arguments against BMD, meanwhile, struggled to keep up with the changing technological basis of the proposed system (interceptor nukes in the '60s, space-based lasers in the ' 80 s, and "bril- liant pebbles" in the '90s) and the changing political environment of the post-Cold War.

And that is where we are today. Slayton convincingly shows that physical arguments against BMD, however plausible and conservative in their assumptions, are sapped of their force by Americans' profound faith in technological progress and the ability of innovation to solve any problem. Software engineers, meanwhile, could perhaps supply a knockout argument, but doing so would undermine their own progressive narrative of increasing program reliability. And so, we are left with a costly, diplomatically divisive system that we have every reason to think cannot work.

\section{References}

1. N. Oreskes, E. M. Conway, Merchants of Doubt: How a Handful of Scientists Obscured the Truth on Issues from Tobacco Smoke to Global Warming (Bloomsbury, New York, 2010); reviewed in (2).

2. P. Kitcher, Science 328, 1230 (2010).

10.1126/science. 1246560

\section{BEHAVIOR}

\section{Coming to Grips with Learning with Others}

\section{Dorothy M. Fragaszy and Yonat Eshchar}

E veryone, it seems, is interested in animals' social lives, including the ways that social partners help others to learn about the world around them and to master skills to thrive in it. Parents and group mates nurturing young animals as they learn to forage (or to fly, to navigate, etc.) are a staple theme of nature documentaries. These often contain gratuitous references by the narrator to teaching or imitation, two processes that lay viewers typically attribute to social species. Such attributions cause behavioral scientists to shudder, because the evidence for both these processes (in the sense that we understand them in humans) in nonhuman species is limited to precious few species and contexts (1).

Perhaps we should not be surprised at widespread anthropomorphic conceptions of social learning in other species. All of us have direct experience with social learning, and our experiential understanding of this process in our own species is reinforced by exposure to a long history of

The reviewers are at the Behavioral and Brain Sciences Program, Department of Psychology, University of Georgia, Athens, GA 30602, USA. E-mail: doree@uga.edu; yonat@ uga.edu learned examination of the topic (for example, in the 20th century, in the works of John Dewey). In contrast, scientific research on social learning in nonhuman animals has blossomed only relatively recently - in the past 40 or so years - as part of the growing fields of animal behavior and evolutionary biology (1-5). It will be some time before we can explain to the general public how social learning works in nonhuman species well enough to displace superficial attributions of humanlike imitation and teaching.

Meanwhile, those trying to understand social learning in nonhuman animals using the tools of science have much work to do. We are coming to understand that social learning is not restricted to large-brained animals but is instead widely distributed-it is present, for example, in crickets (6) - and that it is a powerful participant in evolutionary processes (7). Documenting how social learning contributes to the diversity of animal life is challenging. The field is currently overstocked with proposed categories of social learning processes and understocked with sufficiently powerful analytical paradigms. This state of affairs leaves prospective students of social learning wondering where to start.

Behavioral biologists William Hoppitt (Anglia Ruskin University) and Kevin Laland (University of St Andrews) offer a steady hand to those aspiring to study how social learning works or to understand the relevant scientific literature. To our knowledge, Social Learning is the first authored-rather

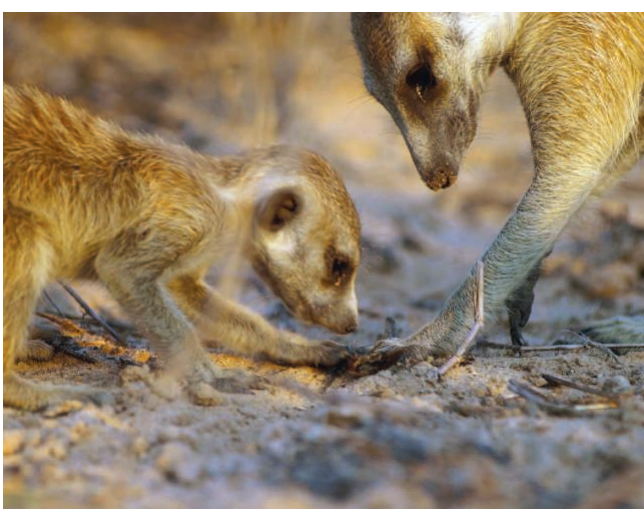

Learning with another. Juvenile meerkat (Suricata suricatta) inspects cricket captured by an adult.

than edited-book devoted specifically to the topic. As such, it is more thematically organized than previous volumes about the subject (1-3). With admirable clarity, the authors review the concepts, experimental designs, and methods used in studies of social learning in nonhuman animals, and they provide suggestions for new analytical approaches 